\title{
Breeding for resistance to facial eczema in dairy cattle
}

\author{
C.A. MORRIS', N.R. TOWERS and H.J. TEMPERO ${ }^{2}$ \\ 'Ruakura Agricultural Centre, Hamilton \\ ${ }^{2}$ Livestock Improvement Corporation Limited, New Zealand Dairy Board, Hamilton
}

\begin{abstract}
Facial eczema (FE) is a disease of grazing ruminants caused by ingesting spores of the fungus Pithomyces chartarum. The spores contain a toxic compound, sporidesmin, which causes liver injury, sensitivity to sunlight andreduced performance in susceptible dairy cattle. The extent of production losses is summarised. Research at Ruakura has demonstrated that the resistance of animals to FE is inherited, with a heritability estimate of 0.31 in dairy cattle. Genetic progress in dairy cattle could bc achieved by progeny testing young bulls, and selecting for use as sires those with the most resistant progeny. However, work over the last decade in sheep at Ruakura has demonstrated the success of selection based on performance testing (i.e. dosing potential sires themselves and using those that are most resistant to the challenge). In January 1990 we began to develop a pcrformance test for use in the preliminary screening of young dairy bulls for $\mathrm{FE}$ resistance. The details of these tests are described.
\end{abstract}

Keywords facial eczema, dairy cattle, performance testing, production loss

\section{Introduction}

Facial eczema (FE) is a disease of grazing ruminants and is common in the autumn in northern New Zealand. It occurs as a result of ingesting spores of the fungus Pithomyces chartarum, which contain the toxic compound, sporidesmin. In susceptible sheep and cattle, the toxin causes liver injury, sensitivity to sunlight and losses of production (e.g. in dairy cattle, Towers \& Smith 1978).

Resistance to FE is a heritable trait in both sheep and dairy cattle. The heritability of FE resistance in sheep was obtained in 1981 (Campbell et al. 1981), with a value of $0.42 \pm 0.09$, and a value $(0.31 \pm 0.10)$ was obtained in dairy cattle in the autumn of 1989 as a result of a natural outbreak of FE (Morris et al. 1990).

The heritable nature of FE resistance in cattle was later confirmed by using semen from a selection of the sires, ranked for FE resistance in autumn 1989, to generate a crop of experimental calves to be dosed with sporidesmin. Thus bulls identified as either Resistant or Susceptible, on the performance of their progeny when exposed to toxic pasture, left progeny groups which performed in similar manner when directly dosed with sporidesmin (Morris et al. 1991). Therefore, genetic progress for increased FE resistance could realistically be achieved in the dairy industry, as has been achieved in the sheep industry (Morris et al. 1989; Towers et al. 1990). This paper describes performance-test procedures alreadyinuseinsheepandourearlyattempts toestablish similar procedures-in-young-dairy-breedbulls.

\section{Materials and methods}

\section{Depression of production}

The effects of sporidesmin intake on milk yields have been recorded in experiments at Ruakura to investigate the toxicity of sporidesmin and the protective effects of zinc dosing. Control (unchallenged) animals have been compared with treated animals, and the effects on milk yield and composition recorded.

\section{Performance testing protocol}

Performance testing of rams is now a well-established practice based on many years of trial results (Towers $\boldsymbol{e t}$ al. 1990). This has led to well-defined procedures and a good understanding of the required sporidesmin dose rates. By contrast we have relatively little experience in working with young cattle, so the first objective of the present studies was to develop a satisfactory testing procedure for 6- to I-month-old bulls, which is not lifethreatening and which does not jeopardise the later collection of semen from these bulls from about 14 months of age onwards.

In a normal FE-resistance performance test with rams, blood samples are collected before dosing, and the animals are then dosed with sporidesmin. Blood samples are collected again about 21 days after dosing, and analysed for the enzyme EC 2.3.2.2, gamma glutamyltransferase (GGT), (Towers \&Stratton 1978). An elevation of more than $30 \%$ above the pre-dose (base) concentration of GGT is taken as indicative of 
liver injury, and of susceptibility of an animal to that dose rate of sporidesmin. Those animals showing no appreciable elevation of GGT may be subjected to a second round of sporidesmin dosing, using a higher level of challenge, in order to provide further information to rank rams at the more resistant end of the distribution (Towers et al. 1983).

The fist attempt at performance testing young bulls was planned for the autumn of 1990, when it was intended that Jersey bulls purchased from the 1989 calf crop by the Livestock Improvement Corporation Limited for progeny testing would be dosed orally with sporidesmin at Newstead. The Jersey breed was chosen to provide links with earlier work during the 1989 FE outbreak (Morris et al. 1990). The same procedure as described for sheep was planned. However, this was abandoned when analyses of blood samples collected before the performance test revealed a high prevalence of pre-existing minor liver injury in one of the two groups of Jersey bulls selected for testing. All five grazing groups at Newstead, including the Friesian bulls, were then sampled, revealing that a widespread natural FE outbreak was in progress in four groups. Further blood samples were taken throughout the autumn to monitor the situation.

In total 171 eight-month-old bulls weremonitored, 96 Friesians and 7.5 Jerseys representing 21 sires. The bulls were grazed in $\mathbf{5}$ separate groups, divided by breed and body size, on pastures which were sprayed up to 3 times with fungicide from early January at twice the normally recommended dose rate. Pasture samples were collected for spore counting from all paddocks when the bulls were moved and at regular intervals whilst grazing any paddock. One of the groups, comprising 39 Friesians in the above totals, has since been excluded from the present summary because it did not show the GGT elevations from pasture challenge experienced by the other four groups (see below).

Sixty Jersey and Friesian bulls born in spring 1990 were dosed in February 1991 at Newstead with sporidesmin at a rate of $0.2 \mathrm{mg}$ sporidesmin $/ \mathrm{kg}$ liveweight. Results from these two grazing groups are also presented below.

\section{Results}

\section{Depression of production}

By comparison with sheep, there are few published data on the depression of production in dairy cows, The effects of clinical facial eczema, i.e. deaths, weight loss and reductions in milk yield, are generally well recognised, but the effects of subclinical FE generally go unnoticed.

\section{Numbers affected in industry survey data}

Some examples of numbers of affected cows or herds are given for years with serious FE outbreaks. In autumn 1968, 24.5\% of cows in a small region in Taranaki with 25400 cows were affected (Steffert 1970 ); $2.6 \%$ of cows died (a quarter by the end of May and three-quarters by the end of the following October) and $7.0 \%$ were culled for FE. In autumn 1981,63\% of North Island herds reported clinical cases of FE, and $5.6 \%$ and $3.6 \%$ of animals in affected herds were slightly or severely affected.respectively (New Zealand Dairy Board 1981). The national cost of the 1981 outbreak to the dairy industry was estimated to be \$17.1 million (Towers 1986: cost in 1981 dollars). In autumn 1989, $72 \%$ of herds in a survey in Northland, Auckland and Taranaki had animals with elevated GGTs; $29 \%$ of the 1523 animals sampled had elevated GGTs (Morris et al. 1990).

\section{Subclinical effects}

Trial work at Ruakura (Towers \& Smith 1978; Towers unpublished) has shown that exposure to low doses of sporidesmin immediately depresses milk yield - even when the toxin intake is too low to cause liver injury. Only one out of 10 cows dosed in late lactation with sporidesmin at $0.26 \mathrm{mg} / \mathrm{kg}$ liveweight showed a rise in GGT. However, the whole group showed an average $40 \%$ peak depression in daily yield, recovering after 10 days. Because of this depression in milk production, it is likely that many of the drops in milkvolume recorded in FE-prone areas during the autumn are the result of sporidesmin ingestion. This applies even in herds where subsequently there are no clinical cases nor elevations in blood GGT levels indicating the presence of subclinical damage. In this and other trials the depression of milk production began immediately after ingestion of the toxin and was accompanied by changes in milk composition similar to those observed after bacterial mastitis (Towers unpublished).

In the industry data reported by Morris et al. (1990) for 43 herds affected by FE, daily yields of milk, fat and protein were depressed by $0.360,0.030$ and $0.019 \mathrm{~kg}$ in April, by an increase in GGT from 30 to $300 \mathrm{IU} / \mathrm{h}$. Over say a 2-month period of serious FE challenge, as on many farms in autumn 1989, these effects would add to a loss of $1.8 \mathrm{~kg}$ of fat and $1.1 \mathrm{~kg}$ protein, or $1.1 \%$ of annual solids production.

\section{Clinical effects}

Towers \& Smith (1978) also administered a high dose rateof $0.63 \mathrm{mg}$ sporidesmin $/ \mathrm{kg}$ to cows. one month later in the lactation than in the low dose rate study described 
above.Milk yields fell from 10 to $1 \mathrm{~kg} /$ day within 4 days, and returned to the control level in about 30 days. In this experiment, $5.8 \mathrm{~kg}$ ofmilkfat (or $3.9 \%$ of lactation yield) was lost due to the challenge. A similar depression was observed by Smith $\boldsymbol{e t}$ al. (1983) who used a dose of 0.30 $\mathrm{mg} / \mathrm{kg}$ in late lactation, although the reduction in daily yield occurred at a slower rate; GGT concentrations rose to an average peak of almost $500 \mathrm{IU} / \mathrm{h}$ in their experiment.

These production losses are additional to any due to overt clinical FE, when photosensitive animals refuse to graze and may need to be dried off.

\section{Carryover effect?}

The carryover effect into maintenance over the dry period and to subsequent early-lactation production yields is not yet well documented. However, in the herds surveyed by Morris et al. (1990), the cows subsequently culled (for whatever reason) in winter 1989 had significantly higher GGTs (average 296 IU/ 1) than those cows remaining in the herd (average 145 IU/1;-mean-difference-in- $\log _{\mathrm{c}}$ GGT- $=-0.35 \pm 0.15$ ). As farmers were not informed of individual GGT values, the results indicated that subclinical FE increased the likelihood of culling.

\section{Performance testing bulls at Newstead : 1990}

The pre-dose GGT test revealed that GGT concentrations were already elevated in the Jersey group selected for performance testing (mean $91 \mathrm{IU} /$, c.f. normal range $<30 \mathrm{IU} / \mathrm{l}$ ). All grazing groups were then screened a week later; mean GGT levels in 4 groups were elevated (average $91 \mathrm{IU} / \mathrm{I}$ ), with one of these groups averaging 213 IU/. The levels continued to rise, averaging 125 IU/ 1 over the four groups on 14 May. However, there were large differences among groups, with one Jersey and one Friesian group being more severely affected than the other Jersey and Friesian groups. Most (78\%) GGT values remained below 500 IU $/$, indicating that the degree of liver injury was not extensive, and no clinical cases were observed. The mean GGTs in the fifth group averaged less than 20 IU/ on all sampling days.

Spore counts remained below 50000 spores/g grass for most of the autumn, but maximal counts of up to 125000 spores/g grass were grazed for a limited period by the more affected groups. These data confirm that the arbitrary threshold spore count of 100000 spores/g (commonly known as the 'danger level') which was originally set to define when clinical cases of FE might be expected in grazing animals is much too high if the aim is to avoid all liver injury (as measured by elevation of GGT).

The GGT data were analysed using a mixed model analysis. Breed differences were not estimable because of the allocation of bulls to grazing groups by breed. Including GGT data for bulls only where the grazing group mean was elevated, the repeatability of GGT concentration between animals was high $(0.80 \pm 0.03)$. Bulls and their sires were ranked for FE resistance, using GGT data combined across those sampling days where the group mean was elevated. There was a tendency for American sires to be ranked at the susceptible end of the GGT distribution, compared with New Zealand-bred sires.

\section{Performance testing bulls at Newstead : 1991}

Although a sporidesmin dose rate was chosen to cause elevations in plasma GGT in only $30-40 \%$ of the bulls, eventually $100 \%$ of the Jerseys and $92 \%$ of the Friesians had elevated GGTs; several developed clinical FE and had to be housed during sunlight hours. This result was most unexpected as the dose rate of $0.2 \mathrm{mg}$ sporidesmin/ $\mathrm{kg}$ liveweight was lower than had been used in any previous work. For example a dose rate of $0.3 \mathrm{mg} / \mathrm{kg}$ hadbeenused in youngercalvesat Ruakura Agricultural Centre 3 months earlier resulting in $86 \%$ having elevated GGTs, but there were no clinical signs of FE (Morris et al. 1991).

Concern about the difficulty of predicting the mean response, and the possible effect on semen production, led to the abandonment of the original plans to performance test further young bulls in 1991 .

\section{Discussion}

Although the programme was curtailed, analyses of the data have shown that resistance to FE is inherited, and performance testing and selection can be applied.

In spite of any culling of cows for production or disease, most of the genetic progress made in the dairy industry is not due to culling cows, but is the result of bull testing, and the selection and use of the top few bulls throughout the industry. Any change in selection goals, e.g. introducing an additional trait such as FEresistance, is more effective through bull than cow selection. Some future options with bulls at Newstead are:

1. buy in a greater number of bull calves than in previous years, performance test them for FE resistance, and then progeny test only the more resistant ones for production and traits other than production (TOP);

2. buy the same number of bull calves as at present, performance test them todetermine theirrelative FE resistance ranking, then progeny test all bulls for production and TOP, and allow the market to determine the relative usage of bulls in FE-prone areas; 
3. progeny test for FE, production and TOP. This is the slower and more costly method. However, the accuracy with which bulls are ranked by progeny testing is greater than in a performance test. The trade-off between cost and accuracy depends on the number of progeny to be sired by proven bulls.

\section{REFERENCES}

Campbell, A.G.; Meyer, H.H.; Henderson, H.V.; Wesselink. C. 1981. Breeding for facial eczema resistance - a progress report. Proceedings of the NZ Society of Animal Production 41: 273-278.

Morris, C.A.; Towers, N.R.; Campbell, A.G.; Meyer, H.H.; Wesselink, C.; Wheeler, M. 1989. Responses achieved in Romney flocks selected for or against susceptibility to facial eczema, 197587. NZjournal of agricultural research 32: 379-388.

Morris, C.A.; Towers, N.R.; Smith, B.L.; Southey, B.R. 1991. Progeny testing bulls for susceptibility to facial eczema. NZ Journal of Agricultural Research 34: 413-417.

Morris, C.A.; Towers, N.R.; Tempero, H.J.; Cox, N.R.; Henderson, H.V. 1990. Facial eczema in Jersey cattle: heritability and correlation with production. Proceedings of theNZSociety of Animal Production 50: 255-259.

New Zealand Dairy Board 1981.57th Farm Production
Report: 1980-81 season.FarmProductionDivision, NZ Dairy Board, Wellington.

Smith, B.L.; Embling, P.P.; Pearce, M.G. 1983. Zinc sulphate in the drinking water of lactating dairy cows for facial eczema control. Proceedings of the $N Z$ Society of Animal Production 43: 217-219.

Steffert,I.J. 1970. Facial eczema: theextent of damage in dairy cows. Dairyfarming annual 22: 95-102.

Towers, N.R. 1986. Facial eczema - problems and successes in control. Proceedings of the $\mathrm{NZ}$ Grassland Association 47: 121-127.

Towers, N.R.; Meyer, H.H.; Campbell, A.G.; Southey, C.A. 1983. Development of aperformance test for the selection of rams having facial eczema tolerant progeny. Proceedings of the NZ Society of Animal Production 43: 221-223.

Towers, N.R.; Morris, C.A.; Southey. C.A. 1990. Breeding for facial eczema resistance in sheep. Proceedings of the Australian Association of Animal Breeding and Genetics 8: 183-186.

Towers, N.R.; Smith, B .L. 1978. The protective effect of zinc sulphate in experimental sporidesmin intoxication of lactating dairy cows. NZ Veterinary Journal 26: 199-202.

Towers, N.R.; Stratton, G.C. 1978. Serum gammaglutamyltransferase as a measure of sporidesmininduced liver damage in sheep. $N Z$ Veterinary Journal 26: 109-112. 